\title{
A Study to Assess the Relationship between Attention Deficit Hyperactivity Disorder and Obstructive Sleep Apnea in Adults
}

\author{
Sean Hesselbacher ${ }^{1,2}$, Akshar A. Aiyer ${ }^{3}$, Salim R. Surani ${ }^{4,5,6}$, Alishah A. Suleman ${ }^{7}$, Joseph Varon ${ }^{8,9}$ \\ 1. Medicine, Hampton Veterans Affairs Medical Center, Hampton, USA 2. Medicine, Eastern Virginia Medical School, \\ Norfolk, USA 3. Pulmonology, Pulmonary Associates, Corpus Christi, USA 4. Internal Medicine, Texas A\&M Health \\ Science Center, Temple, USA 5. Internal Medicine, Corpus Christi Medical Center, Corpus Christi, USA 6. Internal \\ Medicine, University of North Texas, Dallas, USA 7. Internal Medicine: Critical Care, Aga Khan University, Tanzania, \\ TZA 8. Critical Care, United General Hospital, Houston, USA 9. Critical Care, University of Texas Health Science Center, \\ Houston, USA
}

Corresponding author: Sean Hesselbacher, hesselse@evms.edu

\begin{abstract}
The association between obstructive sleep apnea (OSA) and attention deficit hyperactivity disorder (ADHD) is well-established in children. However, there is a paucity of literature regarding this association in adults. The aim of this study was to determine if ADHD is more common in adult patients with OSA. All patients referred to a sleep center for sleep evaluation were administered the Adult ADHD Self-Report Scale and diagnostic polysomnogram. The ADHD screen is considered positive if 4 of 6 questions in part A of the screening questionnaire were answered abnormally. The study population consisted of 194 participants, predominantly male (62\%), Caucasian (54\%), and Hispanic (44\%). OSA was identified in 160 (83\%) of participants, with 116 (60\%) having moderate to severe OSA. The ADHD screen was positive in 37 (19\%) of participants. There was no significant association between the severity of OSA and presence of ADHD symptoms. Patients with OSA who screened positive for ADHD had higher Epworth Sleepiness Scale scores than those that did not. These data suggest that ADHD is more prevalent in patients with OSA, but do not demonstrate a relationship between OSA severity and ADHD symptoms. Interestingly, sleepiness is more prominent in patients with ADHD.
\end{abstract}

Received 09/16/2019

Review began 09/16/2019 Review ended 10/16/2019 Published 10/24/2019

\section{๑) Copyright 2019} Hesselbacher et al. This is an open access article distributed under the terms of the Creative Commons Attribution License CC-BY 3.0., which permits unrestricted use, distribution, and reproduction in any medium, provided the original author and source are credited.
Categories: Neurology, Psychiatry, Pulmonology

Keywords: obstructive sleep apnea, attention deficit hyperactivity disorder, sleepiness

\section{Introduction}

Obstructive sleep apnea (OSA) is a common disease with prevalence ranging between $2-7 \%$ in the middle age population with apnea hypopnea index $(\mathrm{AHI})>5$, and is even higher among the elderly and in patients with cardiovascular complications and metabolic syndrome [1-4]. OSA is characterized by recurrent partial or complete airway obstructions during sleep. OSA has been associated with impaired daytime performance, public health consequences, general health complications, and comorbid psychiatric conditions [5-8].

Attention deficit hyperactivity disorder (ADHD) is thought to be one of the most common psychiatric disorders in adults, with an estimated prevalence of 4.4\% [9]. Adult ADHD may stem from a new diagnosis, though often persists from childhood. Many of the symptoms of ADHD may mimic those of untreated (or inadequately treated) OSA. Studies have correlated the presence and severity of OSA with ADHD in the pediatric population, though there has been very little work reported in adults. We attempted to examine the associations between ADHD and OSA in a population of adults referred for sleep testing.

The primary aim of this study was to determine if ADHD is more common in adult patients with OSA. Secondary objectives were to determine associations between OSA and ADHD in subgroups of adults, including gender, ethnicity, and age groups, and to determine any associations between ADHD and excessive daytime sleepiness (EDS).

\section{Materials And Methods}

Consecutive patients undergoing polysomnography (PSG) at the Baylor College of Medicine Sleep Center in Houston, Texas in 2009 were provided with the ASRS to complete, in addition to standard pre-sleep study paperwork. Inclusion criteria were completion of a diagnostic or split-night sleep study and the ADHD questionnaire, and age $>18$ years. All records meeting inclusion criteria were selected for review; records were excluded if the patient failed to complete either the ASRS or PSG. All procedures performed in studies involving human participants were in accordance with the ethical standards of the institutional and/or national research committee and with the 1964 Helsinki declaration and its later amendments or comparable ethical standards. 


\section{Questionnaires}

At the time of PSG testing, each patient was provided questionnaires to complete, including demographic questions (including self-reported age, gender, and ethnicity), the Epworth Sleepiness Scale (ESS), and the Adult ADHD Self-Report Scale (ASRS) [10, 11]. The ASRS is a validated 18-question screen for adult ADHD, comprised of 2 parts (A and B) [12, 13]. Part A consists of 6 questions; the screen is considered positive for ADHD if 4 of these questions are answered abnormally. The sensitivity of this questionnaire for detection of ADHD in adults has been shown to be $68.7 \%$, with a specificity of $99.5 \%$. Presuming a prevalence of $4.4 \%$, this results in a positive predictive value of $86.3 \%$ and negative predictive value of $98.6 \%$.

\section{Polysomnography}

Sleep studies were performed using attended comprehensive PSG, including recordings of electroencephalogram, electrooculogram, submentalis electromyogram, airflow, respiratory effort, oxygen saturation, anterior tibialis electromyogram, and heart rhythm. Recordings were scored by a technologist manually according to the American Academy of Sleep Medicine Scoring Guidelines and interpreted by a board-certified sleep physician [14].

\section{Statistics}

Comparisons between the means of 2 normally distributed groups were performed with the unpaired ttest. Comparisons between 2 non-normally distributed groups were done with the Mann-Whitney U test. The normality of a group distribution was determined using D’Agostino-Pearson omnibus normality test. Two groups of dichotomous variables were compared with the Fisher's exact test. In defining subgroups for analysis, obesity was defined as a body mass index $\geqslant 30 \mathrm{~kg} / \mathrm{m}^{2}$; ethnicity was broken down into Caucasian and Hispanic groups only, as the others had insufficient numbers to justify subgroup analysis; age was divided at age 50 and 65, which resulted in 3 approximately equal groups (by total numbers); additionally, OSA has been shown to be more severe above age 50 [15]. A P-value of $<0.05$ was considered statistically significant.

\section{Results}

\section{Demographic and clinical characteristics}

A total of 194 unique patients were included in the analyses; 1 patient did not complete the ESS. The mean ( \pm standard deviation) age was $55.6 \pm 13.9$ years; $62 \%$ were male. The self-reported ethnicities were: $54 \%$ Caucasian, 44\% Hispanic, $2 \%$ other. OSA of any severity (AHI $\geqslant 5)$ was identified in 160 ( $82.5 \%$ ) of the patients, with moderate to severe OSA $(\mathrm{AHI} \geqslant 15)$ seen in $116(59.8 \%)$.

\section{Association between OSA and ADHD}

A positive result on the ADHD questionnaire ( $\geqslant 4$ abnormal responses in part $\mathrm{A}$ ) was obtained from 37 (19.1\%) of the patients. As shown in Table 1, there was no significant association between the severity of OSA and a positive screen on the ADHD questionnaire, in that the proportion of patients screening positive for ADHD were similar among those with absent (AHI <5), mild (AHI 5-14.9), and moderate to severe (AHI $\geqslant 15$ ) OSA. Likewise, the presence of a positive ADHD screen was not associated with any significant difference in AHI (25.7 $\pm 22.8, \mathrm{~N}=37$ vs. $30.6 \pm 28.5, \mathrm{~N}=157 ; \mathrm{P}=0.47)$. No significant differences were seen when making these comparisons in the subgroups (gender, ethnicity, obesity status, and age group). 


\section{Cureus}

\begin{tabular}{|c|c|c|c|c|}
\hline & OSA- & Mild OSA+ & OSA(15)+ & P-value \\
\hline All $(n=194)$ & 0.24 & 0.14 & 0.20 & 0.52 \\
\hline Male $(n=120)$ & 0.07 & 0.12 & 0.16 & 0.58 \\
\hline Female $(n=74)$ & 0.37 & 0.16 & 0.28 & 0.34 \\
\hline Caucasian $(n=105)$ & 0.16 & 0.08 & 0.23 & 0.25 \\
\hline Hispanic $(n=85)$ & 0.31 & 0.21 & 0.15 & 0.42 \\
\hline Obese $(n=151)$ & 0.30 & 0.08 & 0.22 & 0.32 \\
\hline Non-obese $(n=41)$ & 0.14 & 0.16 & 0.07 & 0.71 \\
\hline Age $<50(n=66)$ & 0.31 & 0.18 & 0.31 & 0.70 \\
\hline Age $50-64(n=69)$ & 0.17 & 0.24 & 0.15 & 0.74 \\
\hline Age $\geq 65(n=59)$ & 0.17 & 0.00 & 0.13 & 0.27 \\
\hline
\end{tabular}

TABLE 1: Association between OSA severity and ADHD.

*Values are reported as the proportion of patients in each OSA severity group meeting criteria for and abnormal response to the Adult ADHD Self-

Report Scale; statistical comparisons were made using Chi square test.

*OSA-: obstructive sleep apnea is not present; Mild OSA+: obstructive sleep apnea is present with an apnea-hypopnea index (AHI) 5-14.9 events per hour; OSA(15)+: obstructive sleep apnea is present with an $\mathrm{AHI} \geq 15$ events per hour.

\section{Association of ADHD symptoms with sleepiness}

Scores on the ESS were higher in patients that screened positive for ADHD than those that did not (13.4 \pm 6.0 , $\mathrm{N}=37$ vs. $10.0 \pm 5.1, \mathrm{~N}=156 ; \mathrm{P}=0.002$ ), as seen in Figure 1 (black bars). A greater proportion of patients screening positive for ADHD also had an abnormal ESS score of $>10(0.70$ vs $0.42, \mathrm{P}=0.0019)$.

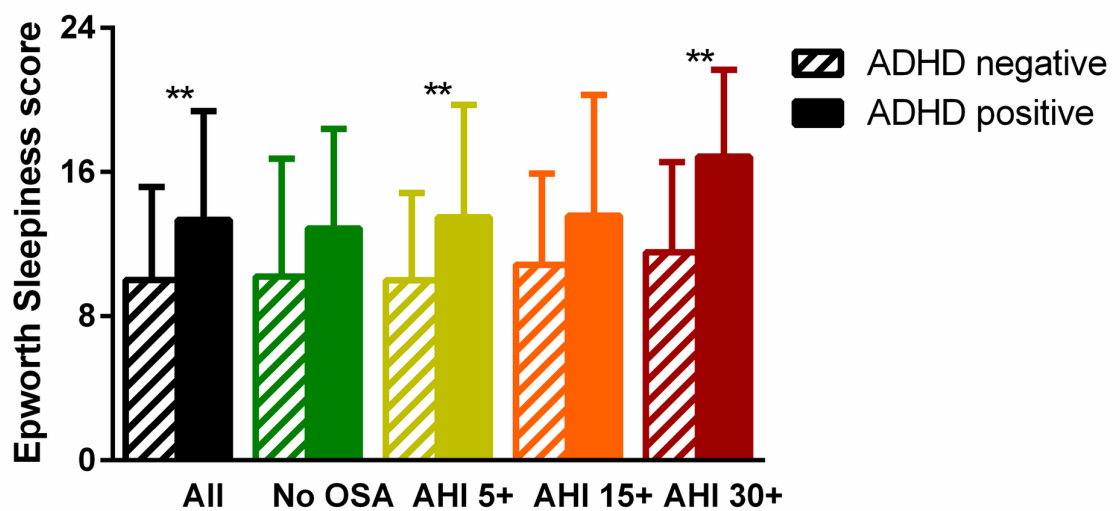

FIGURE 1: Association between symptoms of attention deficit hyperactivity disorder (ADHD) and sleepiness. In patients with obstructive sleep apnea (OSA) of any severity, a positive screen for ADHD (diagonal lines) was associated with higher scores on the Epworth Sleepiness Scale; this was not seen in patients without OSA (solid colors).

${ }^{* *} \mathrm{P}<0.01$

AHI 5+ (yellow): Mild to severe OSA is present with an apnea-hypopnea index $(\mathrm{AHI}) \geq 5$ events per hour.

AHI 15+ (orange): Moderate to severe OSA is present with an $\mathrm{AHI} \geq 15$ events per hour. 
Discussion

Our data shows that in patients with OSA there is a high prevalence of patients screening positive for ADHD (19.1\%) - this is substantially higher than the reported prevalence of ADHD in the general population (4.4\%). Given the previously reported characteristics of the ASRS, a positive result would be expected in approximately $7.3 \%$ of respondents from the general population. Our data did not demonstrate a significant relationship between the severity of OSA and the presence of ADHD symptoms.

The data did show that patients OSA who had ADHD symptoms were, on average, sleepier than those without ADHD symptoms and a greater percentage of ADHD patients had abnormal ESS scores. Previous trials have shown that adults with ADHD tend to have greater subjective sleepiness and our data are consistent with these findings [16]. While none of the questions in part A of the ASRS directly pertain to daytime sleepiness, many can result from sleepiness or poor sleep. It is not hard to imagine someone with EDS having "trouble wrapping up the final details of a project, once the challenging parts have been done" (question 1). Similarly, patients with EDS and sleep disorders often have difficulty remembering appointments or obligations (question 3), and have trouble with organization (question 2) [17, 18]. The other questions relate less directly to EDS. Question 5 ("How often do you fidget or squirm with your hands or feet when you have to sit down for a long time?") may be answered affirmatively in patients with Restless Legs Syndrome, which has been reported to be more common in patients with OSA [19]. If EDS were to contribute to abnormal answers on even some of these questions, the likelihood of a positive screen would be raised, even in the absence of overt ADHD. Because some questions on the ASRS focus on attention deficits and others on hyperactivity, future research may examine which of the questions, including Part B of the ASRS, are most associated with EDS or other sleep disorders, and whether these truly represent the spectrum of ADHD or simply false-positive results.

Previous reports have commented on the overlap between ADHD symptoms and those attributed to OSA, though these have primarily been in children and adolescents [20,21]. Our study is consistent with this in that we saw a much higher prevalence of ADHD than the general population of adults. More study would be needed to determine if ADHD assessment is justified in all patients with OSA.

\section{Conclusions}

We saw a high prevalence of ADHD in a population of OSA patients referred for sleep study testing. Despite no relationship to OSA severity, patients with positive ADHD symptoms were generally sleepier than those without ADHD, suggesting a shared common pathophysiologic neurobehavioral influence. The exact mechanisms underlying this shared vulnerability to sleep disruption may need to be further elucidated.

\section{Additional Information \\ Disclosures}

Human subjects: Consent was obtained by all participants in this study. Animal subjects: All authors have confirmed that this study did not involve animal subjects or tissue. Conflicts of interest: In compliance with the ICMJE uniform disclosure form, all authors declare the following: Payment/services info: All authors have declared that no financial support was received from any organization for the submitted work. Financial relationships: All authors have declared that they have no financial relationships at present or within the previous three years with any organizations that might have an interest in the submitted work. Other relationships: All authors have declared that there are no other relationships or activities that could appear to have influenced the submitted work.

\section{References}

1. Peppard PE, Young T, Barnet JH, Palta M, Hagen EW, Hla KM: Increased prevalence of sleep-disordered breathing in adults. Am J Epidemiol. 2013, 177:1006-1014. 10.1093/aje/kws342

2. Punjabi NM: The epidemiology of adult obstructive sleep apnea. Proc Am Thorac Soc. 2008, 5:136-143. 10.1513/pats.200709-155MG

3. Young T, Palta M, Dempsey J, Peppard PE, Nieto FJ, Hla KM: Burden of sleep apnea: Rationale, design, and major findings of the Wisconsin Sleep Cohort study. WMJ. 2009, 108:246-249.

4. Young T, Peppard PE, Gottlieb DJ: Epidemiology of obstructive sleep apnea. Am J Respir Crit Care Med. 2002, 165:1217-1239. 10.1164/rccm.2109080

5. Monahan K, Redline S: Role of obstructive sleep apnea in cardiovascular disease . Curr Opin Cardiol. 2011, 26:541-547. 10.1097/HCO.0b013e32834b806a

6. Punjabi NM, Caffo BS, Goodwin JL, et al.: Sleep-disordered breathing and mortality: A prospective cohort study. PLoS Med. 2009, 6:1000132-1000132. 10.1371/journal.pmed.1000132

7. Sharafkhaneh A, Giray N, Richardson P, et al.: Association of psychiatric disorders and sleep apnea in a large cohort. Sleep. 2005, 28:1405-1411. 10.1093/sleep/28.11.1405

8. Tregear S, Reston J, Schoelles K, Phillips B: Obstructive sleep apnea and risk of motor vehicle crash: 
Systematic review and meta-analysis. J Clin Sleep Med. 2009, 5:573-581.

9. Kessler RC, Adler L, Barkley R, et al.: The prevalence and correlates of adult ADHD in the United States: Results from the National Comorbidity Survey Replication. Am J Psychiatry. 2006, 163:716-723.

10.1176/ajp.2006.163.4.716

10. Johns MW: A new method for measuring daytime sleepiness: The Epworth Sleepiness Scale . Sleep. 1991, 14:540-545. 10.1093/sleep/14.6.540

11. Adult ADHD Self-Report Scale (ASRS-v1.1) Symptom Checklist. Accessed: August 15, 2018: https://add.org/wp-content/uploads/2015/03/adhd-questionnaire-ASRS111.pdf..

12. Kessler RC, Adler L, Ames M, et al.: The World Health Organization Adult ADHD Self-Report Scale (ASRS): A short screening scale for use in the general population. Psychol Med. 2005, 35:245-256. 10.1017/S0033291704002892

13. Kessler RC, Adler LA, Gruber MJ, Sarawate CA, Spencer T, Van Brunt DL: Validity of the World Health Organization Adult ADHD Self-Report Scale (ASRS) Screener in a representative sample of health plan members. Int J Methods Psychiatr Res. 2007, 16:52-65. 10.1002/mpr.208

14. Iber C, Ancoli-Israel S, Chesson A, Quan S, American Academy of Sleep Medicine: The AASM Manual for the scoring of sleep and associated events: Rules, terminology and technical specifications. American Academy of Sleep Medicine, Westchester; 2007.

15. Kiral N, Salepçi B, Fidan A, et al.: Relationship between obstructive sleep apnea syndrome severity and age . Eur Respir J. 2011, 38:2190.

16. Sobanski E, Alm B, Hennig O, Riemann D, Feige B, Schredl M: Daytime sleepiness in adults with ADHD: A pilot trial with a multiple sleep latency test. J Atten Disord. 2016, 20:1023-1029. 10.1177/1087054714529456

17. Hershner SD, Chervin RD: Causes and consequences of sleepiness among college students . Nat Sci Sleep. 2014, 6:73-84. 10.2147/NSS.S62907

18. Lis S, Krieger S, Hennig D, et al.: Executive functions and cognitive subprocesses in patients with obstructive sleep apnoea. J Sleep Res. 2008, 17:271-280. 10.1111/j.1365-2869.2008.00660.x

19. Naëgelé B, Thouvard V, Pépin J-L, et al.: Deficits of Cognitive Executive Functions in Patients With Sleep Apnea Syndrome. Sleep. 1995, 18:43-52. 10.1093/sleep/18.1.43

20. Oğuztürk Ö, Ekici M, Çimen D, Ekici A, Senturk E: Attention deficit/hyperactivity disorder in adults with sleep apnea. J Clin Psychol Med Settings. 2013, 20:234-239. 10.1007/s10880-012-9331-2

21. Youssef NA EM, Angly SS, Strauss JL, Marx CE: Is obstructive sleep apnea associated with ADHD? . Ann Clin Psychiatry. 2011, 23:213-224. 